\title{
Controlled synthesis and characterization of hollow flower-like silver nanostructures
}

\author{
This article was published in the following Dove Press journal: \\ International Journal of Nanomedicine \\ 19 March 2012 \\ Number of times this article has been viewed
}

\section{Kamel AM Eid \\ Hassan ME Azzazy}

Novel Diagnostics and Therapeutics Group, Yousef Jameel Science and Technology Research Center, School of Sciences and Engineering, The American University in Cairo, New Cairo, Egypt
Correspondence: Hassan ME Azzazy School of Sciences and Engineering, The American University in Cairo, AUC Avenue, PO Box 74, New Cairo I I835, Egypt Tel +20 226152559 (work); +20 100565727 (cell) Fax +20 227957565

Email hazzazy@aucegypt.edu
Background: The synthesis of anisotropic silver nanoparticles is a time-consuming process and involves the use of expensive toxic chemicals and specialized laboratory equipment. The presence of toxic chemicals in the prepared anisotropic silver nanostructures hindered their medical application. The authors have developed a fast and inexpensive method for the synthesis of threedimensional hollow flower-like silver nanostructures without the use of toxic chemicals.

Methods: In this method, silver nitrate was reduced using dextrose in presence of trisodium citrate as a capping agent. Sodium hydroxide was added to enhance reduction efficacy of dextrose and reduce time of synthesis. The effects of all four agents on the shape and size of silver nanostructures were investigated.

Results: Robust hollow flower-like silver nanostructures were successfully synthesized and ranged in size from $0.2 \mu \mathrm{m}$ to $5.0 \mu \mathrm{m}$ with surface area between $25-240 \mathrm{~m}^{2} / \mathrm{g}$. Changing the concentration of silver nitrate, dextrose, sodium hydroxide, and trisodium citrate affected the size and shape of the synthesized structures, while changing temperature had no effect.

Conclusion: The proposed method is simple, safe, and allows controlled synthesis of anisotropic silver nanostructures, which may represent promising tools as effective antimicrobial agents and for in vitro diagnostics. The synthesized hollow nanostructures may be used for enhanced drug encapsulation and sustained release.

Keywords: silver nanoparticles, 3D hollow, flower-like, green synthesis

\section{Introduction}

Silver nanoparticles have unique optophysical properties ${ }^{1}$ and have been used as catalysts and antimicrobial, antiseptic, and imaging agents. ${ }^{2-6}$ Applications of nanostructures depend on their size and shape. ${ }^{6}$ Development of new methods for synthesis of nanostructures that allow control of size and shape are necessary to generate new nanostructures that can be employed in various applications. Hollow nanostructures were used to encapsulate and control release of drugs, ${ }^{7,8}$ cosmetics, and nucleic acids, ${ }^{9}$ and have enhanced catalytic properties owing to their large surface area. ${ }^{10,11}$ Self-assembly of anisotropic silver nanostructures has been used for synthesis of biomaterials and semiconductor copolymers; however, controlling shape and size of such structures is still a challenge. ${ }^{12-14}$

There are several methods for fabrication of silver nanostructures with different shapes such as nanowires, ${ }^{15}$ nanorods, ${ }^{16,17}$ and nanotubes. ${ }^{15}$ However, these methods employ polymers (such as polyvinyl pyrrolidone or polyethylene glycol), toxic surfactants (such as cetyltrimethylammonium bromide, benzyldodecyldimethylammonium chloride), and reducing agents (such as sodium borohydride). ${ }^{17-19}$ Therefore, there is a need to 
develop new methods for safe and inexpensive synthesis of anisotropic silver nanostructures.

The authors have developed a fast, inexpensive, and safe method for the synthesis of three-dimensional (3D) hollow flower-like silver nanostructures which may be useful in medical applications. The synthesized hollow structures with higher pore areas may have enhanced drug encapsulation capacity and can be used for sustained release of drugs. The method employs nontoxic degradable chemicals and allows control of size and shape of the synthesized structures.

\section{Materials and methods}

\section{Materials}

Silver nitrate $\left(\mathrm{AgNO}_{3}\right)$, trisodium citrate (TSC), dextrose, and sodium hydroxide $(\mathrm{NaOH})$ were purchased from Sigma-Aldrich Chemie GmbH (Munich, Germany). Hydrogen chloride and nitric acid were purchased from El-Gomhouria Co, (Cairo, Egypt). Double deionized water (DDI) was prepared using a Milli-Q ${ }^{\mathrm{TM}}$ system (Direct-Q 3, Model ZRQS0P0WW, Millipore Corporation, Billerica, MA) with a resistivity of $18 \mathrm{M} \Omega \mathrm{cm}$.

\section{Synthesis of 3D hollow silver flower-like nanostructures}

The hollow flower-like structures were synthesized by the chemical reduction of $\mathrm{AgNO}_{3}$ in aqueous solution. Briefly, a round-bottom flask was cleaned thoroughly with aqua regia (3:1 hydrogen chloride:nitric acid) then rinsed with DDI water. $\mathrm{AgNO}_{3}(2-8 \mu \mathrm{M})$ was added to 3-9 mM dextrose solution and dissolved in water at room temperature. $\mathrm{NaOH}$ (0.01 mM) was added during stirring. The solution color changed from colorless to deep green, brown, yellow, or gray depending on the amount of $\mathrm{AgNO}_{3}$, dextrose, $\mathrm{NaOH}$, and TSC (1-6 mM). Following color change, the solution was stirred for an additional 5 minutes, centrifuged, and washed three times with DDI water to remove excess dextrose.

\section{Characterization of silver nanostructures} Scanning electron microscope

The size and morphology of the synthesized silver nanostructures were studied using scanning electron microscope (LEO SUPRA $^{\circledR}$ 55; Carl Zeiss AG, Oberkochen, Germany). The samples were mounted on a silicon slide and left 2 hours to dry before imaging without sputter coating; particle size was reported as the mean diameter of randomly selected structures.

\section{Spectrophotometry}

The samples of the prepared silver nanostructures were diluted to $1 / 10$ times in DDI water, and $\lambda$ max measured using LAMBDA 950 spectrophotometer (PerkinElmer, Waltham, MA).

\section{Nitrogen isothermal adsorption}

Nitrogen isothermal adsorption was measured at $77 \mathrm{~K}$ on an $\mathrm{ASAP}^{\circledR} 2010$ porosimeter (Micromeritics Instrument Corporation, Norcross, GA). The surface area was estimated by using the Brunauer-Emmett-Teller equation to measure surface area. The pore size, volume, and area distribution were calculated using the Barrett-JoynerHalenda equation.

\section{Atomic force microscope}

The 3D morphology, surface area, and roughness of the prepared silver anisotropic nanostructures were studied using atomic force microscope (VEECO Dimension 3100 Scanning Probe Microscope, Veeco Instruments, Inc, Plainview, NY). The samples were mounted on a silicon slide and left 2 hours to dry before imaging.

\section{Results and discussion}

The size and shape of the synthesized silver nanostructures were studied using scanning electron microscopy and particle size was reported as mean diameter of randomly selected structures, as shown in Figures 1 and 2. Figure 1 (A-I) presents micrographs of samples prepared using varying concentrations of $\mathrm{AgNO}_{3}$, dextrose, and $\mathrm{NaOH}$. Figure 1 (A-C) presents 3D hollow silver nanostructures synthesized using different concentrations of $\mathrm{AgNO}_{3}$ ranging between 2-8 $\mu \mathrm{M}$. The particles have a 3D hollow flower-like shape, with branched edges and highly rough surface and particle size ranging between $0.2-0.5 \mu \mathrm{m}$ with interconnected pores in the range of 50-200 $\mathrm{nm}$ diameters (Figure 3). Pore interconnection, distribution, roughness, and branched edges increased with increasing $\mathrm{AgNO}_{3}$ concentration.

Figure 1 (D-F) presents samples prepared with varying concentrations of dextrose ranging between 3-9 mM. The particles have a 3D hollow flower-like shape with more branched edges, highly rough surface, and more multilayers and interconnected channels with ordered cross layers. Particle size ranged between 0.3-1.0 $\mu \mathrm{m}$ (Figure 3). Particles had distributed internal pores in the range of 20-80 nm. Layer distribution, order, and interconnection increased with increasing dextrose concentration while branched edges decreased with increasing dextrose.

Figure $1(\mathrm{G}-\mathrm{I})$ presents samples prepared by varying $\mathrm{NaOH}$ concentration ranging between $0.1-0.5 \mathrm{mM}$. Particles have a 3D hollow flower shape with highly branched edges, 

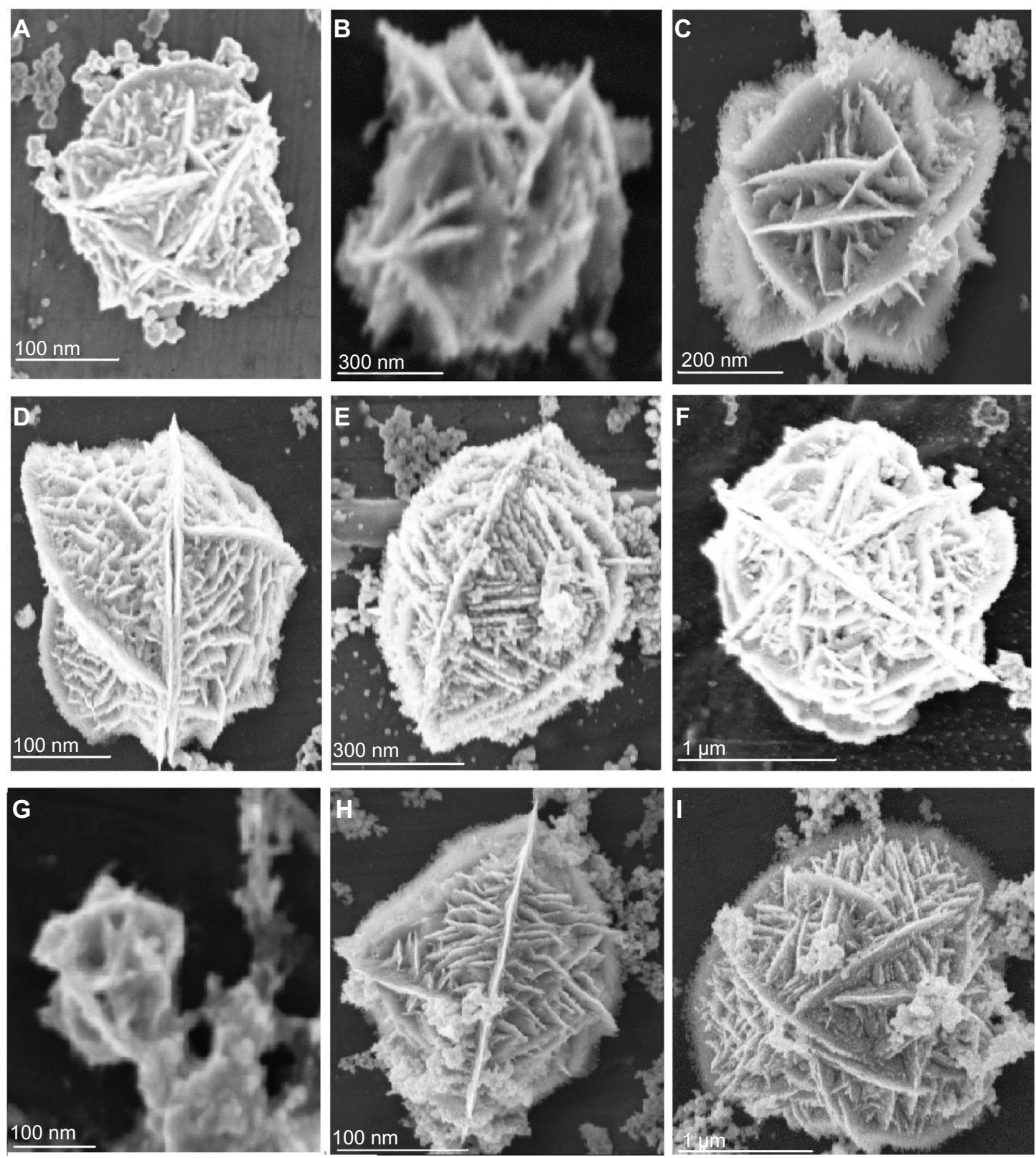

Figure I Scanning electron microscopy of flower-like silver nanostructures. Structures prepared by varying concentrations of different reagents. (A-C): silver nitrate 2-8 $\mu \mathrm{M}$, dextrose $3 \mathrm{mM}$, and sodium hydroxide $0.1 \mathrm{mM}$; (D-F): silver nitrate $2 \mu \mathrm{M}$, dextrose 3-9 mM, and sodium hydroxide $0.1 \mathrm{mM}$; (G-I) silver nitrate $2 \mu \mathrm{M}$, dextrose $3 \mathrm{mM}$, and sodium hydroxide $0.1-0.5 \mathrm{mM}$.

highly rough surface, and elongated multilayers. Particle size ranged between $0.2-1.6 \mu \mathrm{m}$ (Figure 3 ) with distributed pores in the range of $50-100 \mathrm{~nm}$. The layers, pores, interconnection, and branched edges increased with increasing $\mathrm{NaOH}$ concentration.

Figure $2(\mathrm{~J}-\mathrm{M})$ presents samples prepared with varying concentrations of TSC ranging between 1-6 mM. Particles have a flower-like shape with size between $0.45-2.3 \mu \mathrm{m}$ (Figure 3). Increasing TSC concentration above $6 \mathrm{mM}$ resulted in large multiwall hollow scaffold-like structures that ranged in size between 3.0-5.0 $\mu \mathrm{m}$ (Figure 3).
Experiments were repeated several times and reproducible results were obtained indicating the ability to synthesize 3D hollow flower-like silver nanostructures with the ability to control their sizes and shapes by varying the concentrations of the four chemicals discussed above.

It should be noted that carrying out the syntheses at different temperatures, between $25^{\circ} \mathrm{C}$ and $70^{\circ} \mathrm{C}$, alone or in combination with varying concentrations of different chemicals had no effect on particle size or shape.

The ultraviolet-visible spectra (Figure 4A) of samples prepared with varying concentrations of $\mathrm{AgNO}_{3}$ (Figure 1A-C) 

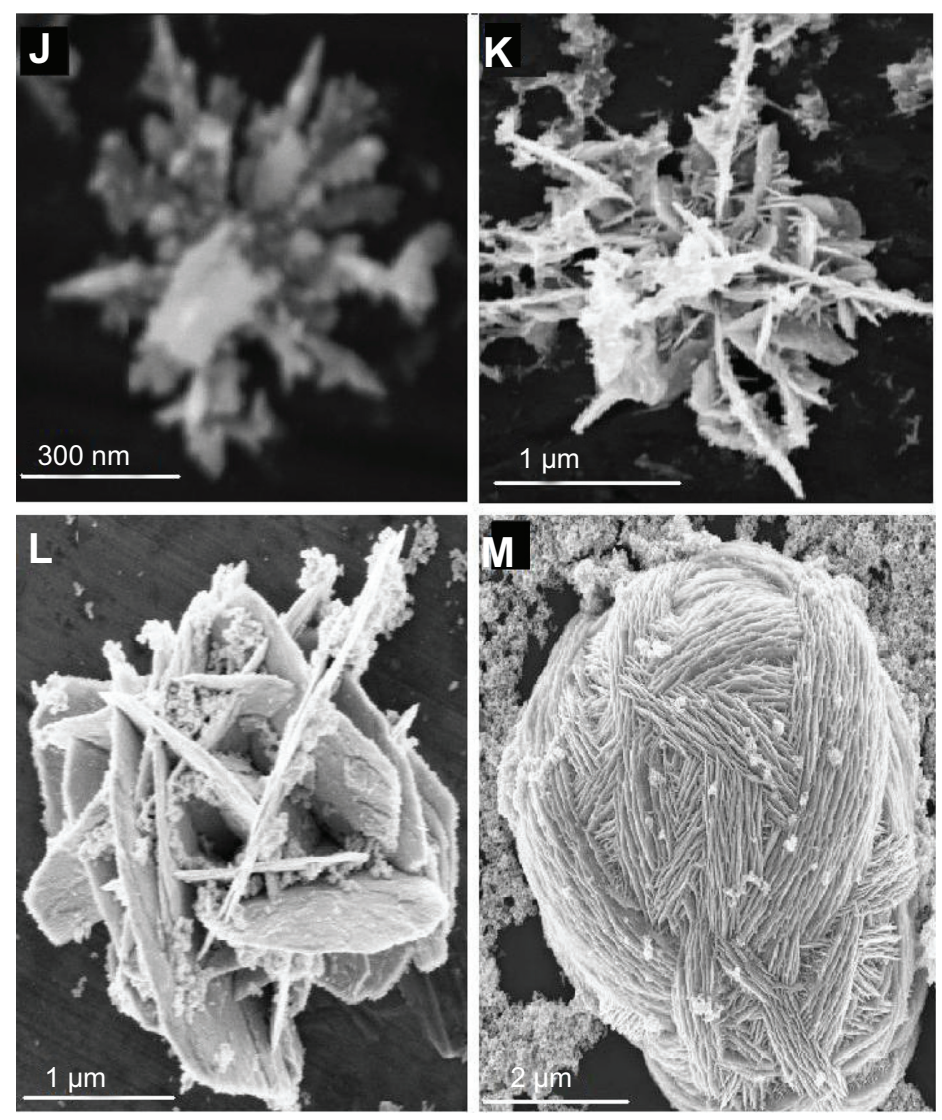

Figure 2 Scanning electron microscopy of flower-like silver nanostructures. (J-M) represent structures prepared by using silver nitrate $2 \mu \mathrm{M}$, dextrose $3 \mathrm{mM}$, sodium hydroxide $0.1 \mathrm{mM}$, and trisodium citrate $1-6 \mathrm{mM}$.
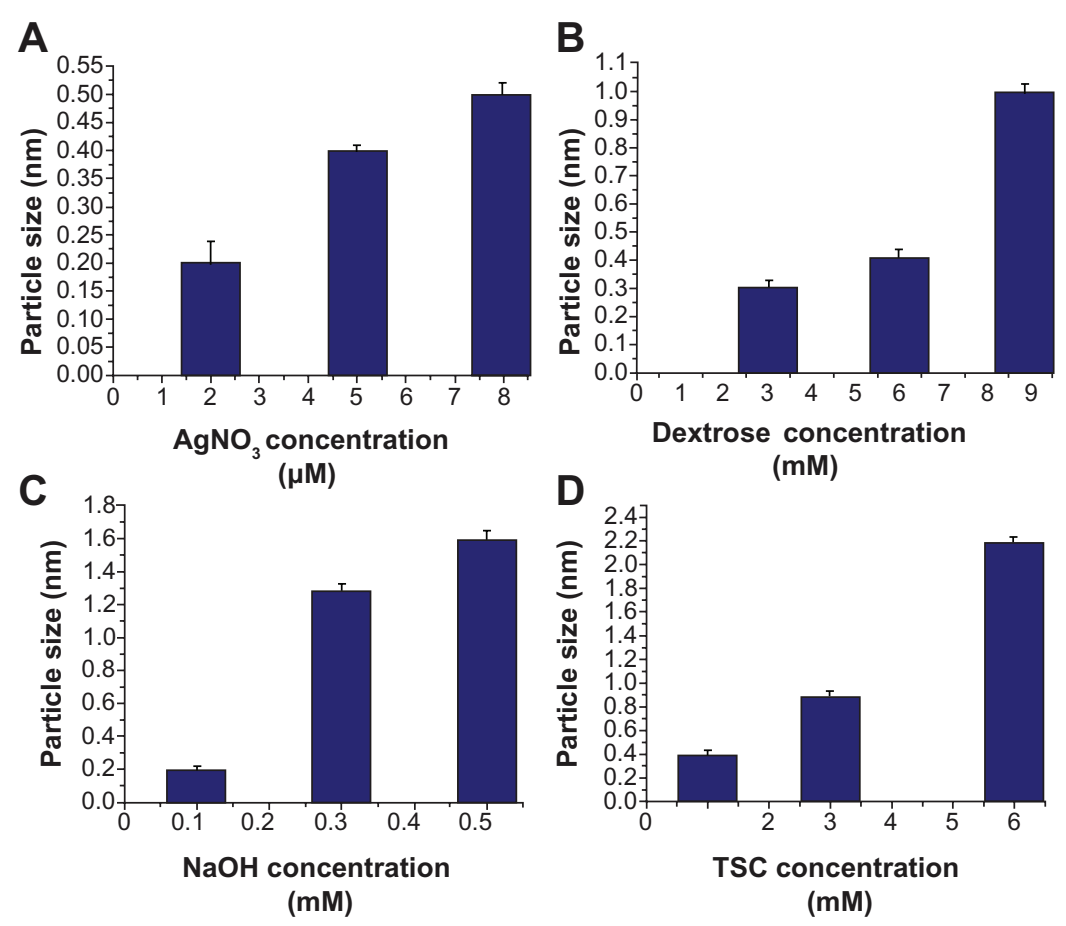

Figure 3 Particle size distributions using various concentrations of silver nitrate (A), dextrose (B), sodium hydroxide (C), or trisodium citrate (D). Abbreviations: $\mathrm{AgNO}_{3}$, silver nitrate; $\mathrm{NaOH}$, sodium hydroxide; $\mathrm{TSC}$, trisodium citrate. 
A

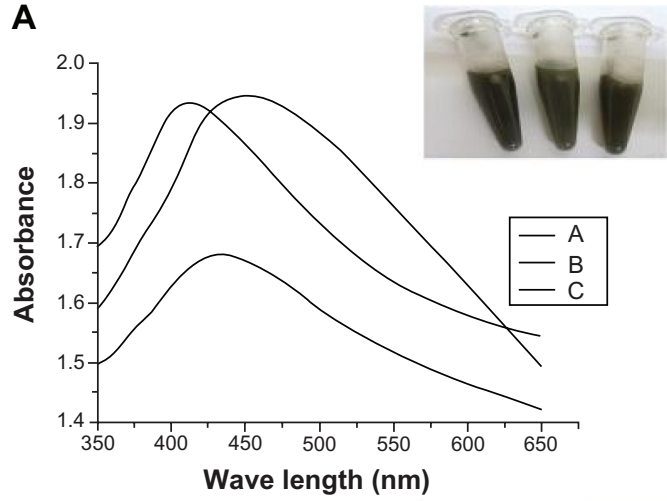

C

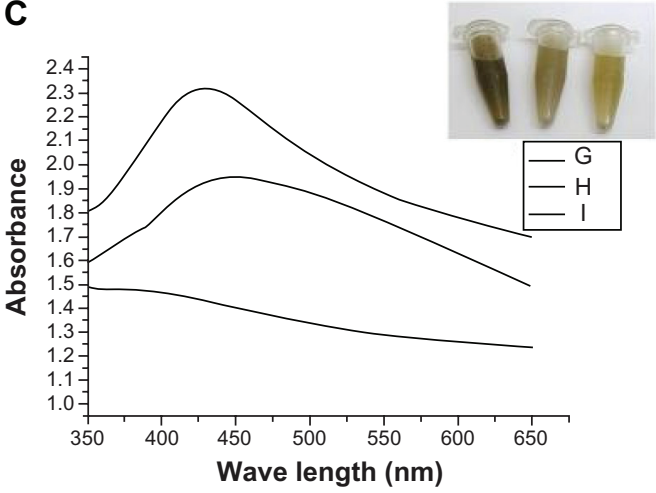

B

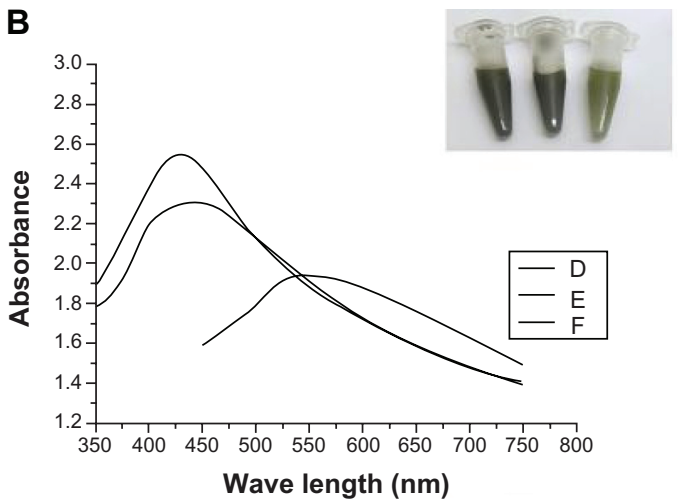

D

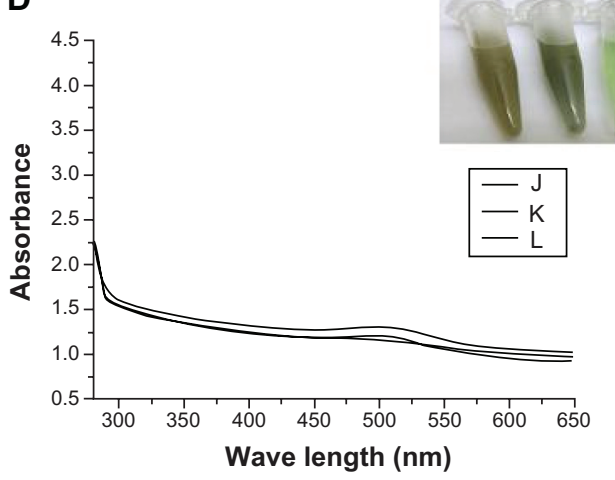

Figure 4 Ultraviolet absorbance spectra of flower-like silver nanostructures prepared using varying concentrations of silver nitrate (A), dextrose (B), sodium hydroxide (C), or trisodium citrate (D).

showed absorption maxima between 410-450 nm. Samples prepared with varying dextrose concentration showed absorbance bands at $430 \mathrm{~nm}, 450 \mathrm{~nm}$, and 450-500 nm (Figure 4B). Figure 4C shows absorption spectra of samples prepared with varying $\mathrm{NaOH}$ concentrations where absorption maxima were detected between 410-600 nm. Figure 4D shows spectra of samples prepared with varying concentrations of TSC where two absorption bands were detected at 280-300 $\mathrm{nm}$ and 500-525 nm. Increasing concentrations of $\mathrm{AgNO}_{3}$, dextrose, $\mathrm{NaOH}$, or TSC resulted in increased size of silver nanostructures, which was reflected by the shift of absorbance bands to longer wavelength.

Silver nanostructures were investigated by atomic force microscopy where surface area, roughness, and surface area diffraction were $49.37 \mathrm{~nm}^{2}, 33.5 \mathrm{~nm}$, and $14.6 \%$, respectively (Figure 5). Atomic force microscopy studies confirmed the $3 \mathrm{D}$ structures of the silver particles.

Figure 6 (A-D) shows the surface area, pore size, pore area, and pore area relative to varying concentrations of dextrose. Porosimetry studies indicated that the surface area of 3D hollow flower-like nanostructures is high $\left(25-240 \mathrm{~m}^{2} / \mathrm{g}\right)$ due to the presence of interconnected pores. The pore area increased with increased dextrose concentration.

\section{Conclusion}

The dextrose acted as a reducing agent of $\mathrm{AgNO}_{3}$ and as a preliminary capping material. TSC acted as a capping material and together with dextrose enhanced silver dispersion and directed growth of particles to highly anisotropic structures. Growth of particles depended upon concentrations of dextrose and TSC adsorbed on the surface of silver particles. $\mathrm{NaOH}$ augmented reduction and supported growth of nanoparticles to 3D hollow flower-like structures.

The uniformity of size and shape of the 3D hollow flowerlike silver nanostructures can be controlled by manipulating $\mathrm{AgNO}_{3}$, dextrose, $\mathrm{NaOH}$, and/or TSC concentrations. The smallest flower-like nanostructures (up to $200 \mathrm{~nm}$ ) were prepared by using $2 \mu \mathrm{M} \mathrm{AgNO}, 3 \mathrm{mM}$ dextrose, and $0.01 \mathrm{mM} \mathrm{NaOH}$. Porosimetry analysis showed 3D hollow nanostructures with high surface area ranging between $25-240 \mathrm{~nm}^{2} / \mathrm{g}$ and pore area increased with increasing dextrose concentration. Atomic force microscopy studies indicated that the prepared particles have 3D structures with surface roughness of $33.5 \mathrm{~nm}$ and surface area diffraction of $14.6 \%$. Because of their unique properties and ease of preparation, the prepared structures may serve as superior 


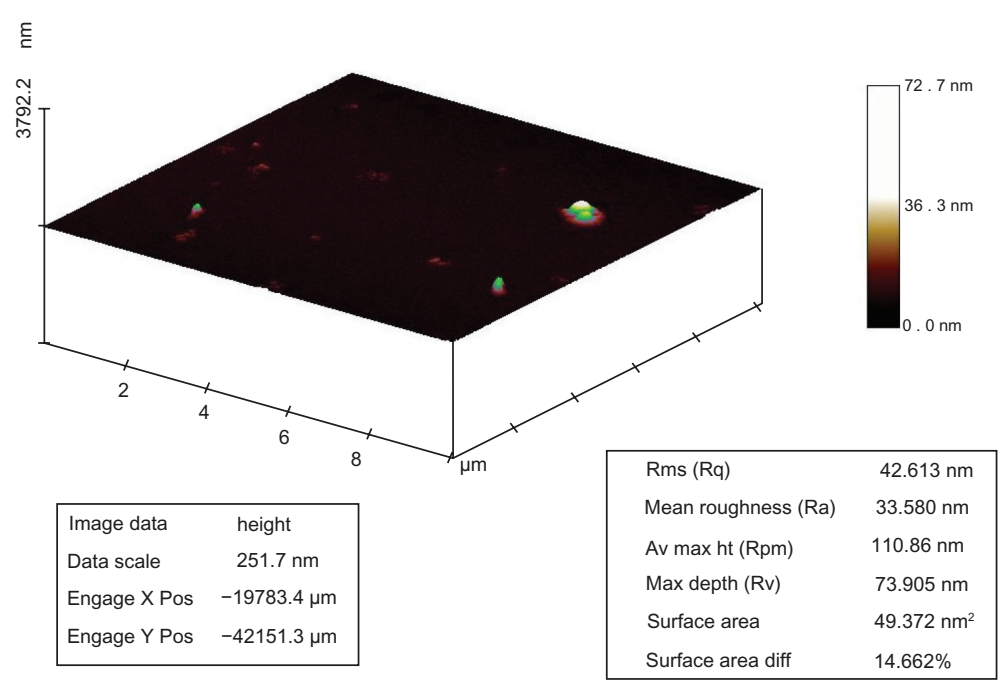

Figure 5 Atomic force microscopy analysis of silver nanostructures. Sample prepared by reacting silver nitrate $2 \mu \mathrm{M}$, dextrose $3 \mathrm{mM}$, and sodium hydroxide $0.1 \mathrm{mM}$. Surface area, roughness, and surface area diffraction were $49.37 \mathrm{~nm}^{2}, 33.5 \mathrm{~nm}$, and $14.6 \%$, respectively.

vehicles for long-term release of drugs and effective antimicrobial agents and also hold the promise as effective tools for catalysis.

The use of nanoparticles as drug carriers is limited by the toxicity of used reagents, the limited control of pore size and area, and the cost of particle synthesis. ${ }^{20,21}$ The newly developed method allows effective control of structure porosity, employs environmental friendly reagents, and is fast and inexpensive. Therefore, the synthesized anisotropic structures could open new frontiers as efficient and
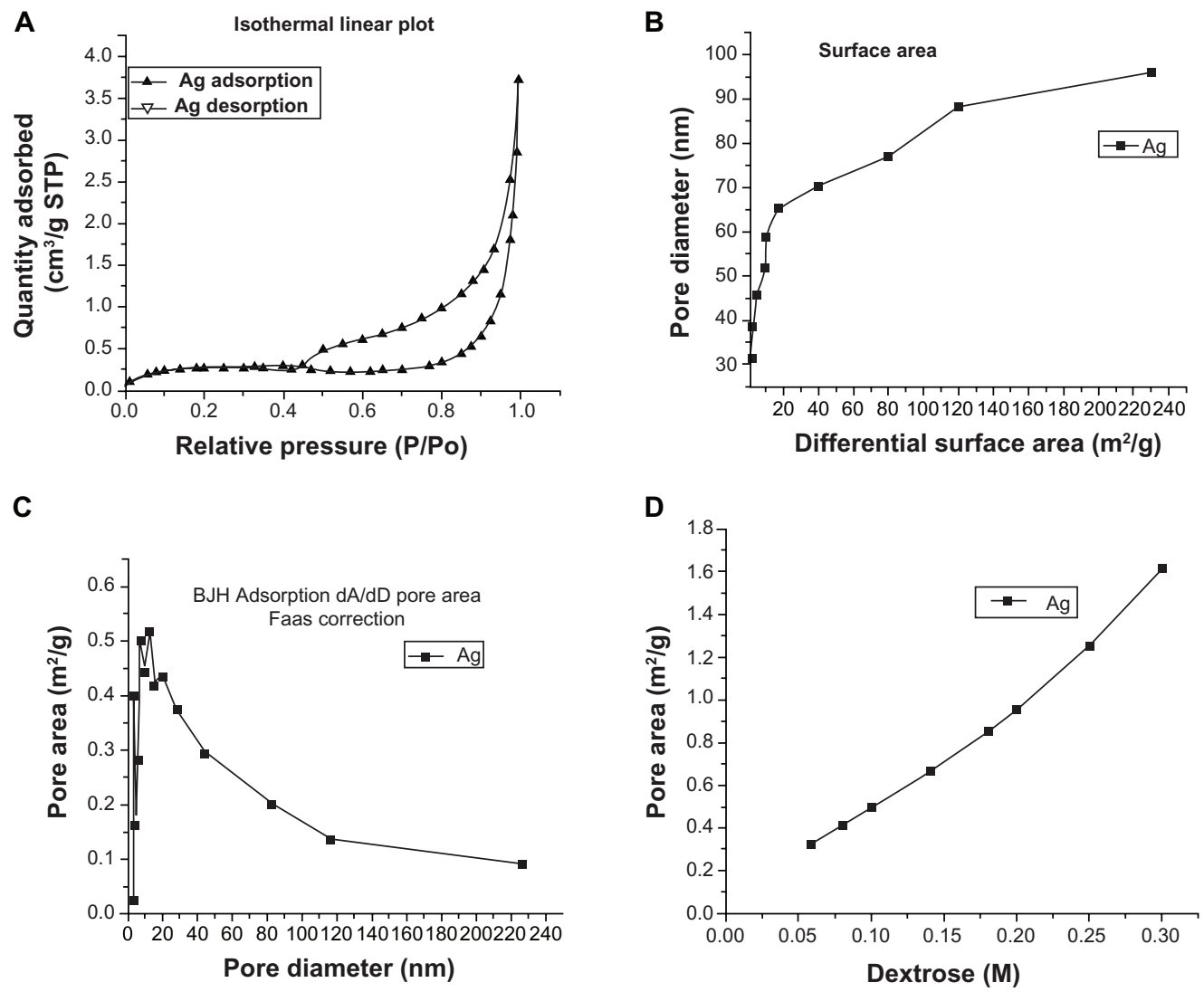

Figure 6 Porosimetry analysis of silver nanostructures. (A) Isothermal linear plot showing adsorbed and desorbed liquid nitrogen on silver nanostructures relative to pressure; (B) surface area calculated by plotting pore diameter against differential surface area; (C) pore area calculated by Barrett-Joyner-Halenda adsorption model and flame atomic absorption spectrometry correction; (D) pore area relative to dextrose concentration. 
safe drug carriers. As compared to spherical or nonporous nanoparticles, porous drug carriers with pore size in the range of 5-100 $\mathrm{nm}$ provide a larger surface area and improve drug dissolution and encapsulation efficacy. ${ }^{22,23}$ Noteworthy is the fact that porous nanostructures have allowed the encapsulation of large amounts of biomolecules such as peptides and nucleic acids within a relatively small carrier material mass. The new silver flower-like silver nanostructures have interconnected pores and pore size of 50-200 nm. Their enhanced porosity is predicted to allow improved drug encapsulation and loading capacity and allow their use for sustained drug release.

The antimicrobial effects of silver particles have been correlated to their large surface area which enhances their interaction with microorganisms as well as their stability in bacterial growth medium. Additionally, silver nanoparticles with different shapes have been shown to have different effects on bacteria. For spherical nanoparticles, a total silver content of $12.5 \mu \mathrm{g}$ was needed to show bacterial inhibition, whereas rod-shaped particles needed a total of 50-100 $\mu \mathrm{g}$ of silver content to show a similar effect. ${ }^{24}$ The new silver nanostructures have very large surface areas and were stable in solution up to 1 month after synthesis, and thus are predicted to have enhanced antibacterial effect. The antibacterial effect of the synthesized flower-like nanostructures will be investigated.

Silver nanoparticles exhibit enhanced absorbance and scattering properties. These properties are dependent on particle shape and size and have been utilized for clinical diagnostics. Zhou et al used triangular silver nanoparticle arrays for spectroscopic detection of p53, a marker of neck squamous cell carcinoma, in serum. ${ }^{25}$ Also, Shanmukh et al developed a spectroscopic assay, based on surface enhanced Raman scattering, using silver nanorod arrays for detection and characterization of respiratory viruses. ${ }^{26}$ Therefore, silver flower-like structures with their unique shape and controlled size warrant further investigation for potential utilization in clinical diagnostics.

\section{Acknowledgments}

The authors acknowledge Ms Mai Mansour (Yousef Jameel Science and Technology Research Center) for her editorial support and Mr Ramy Wasfy (Yousef Jameel Science and Technology Research Center) for his help with scanning electron microscopy. This work has been funded by a grant from Mr Yousef Jameel to Hassan Azzazy.

\section{Disclosure}

The authors report no conflicts of interest in this work.

\section{References}

1. Burda C, Chen X, Narayanan R, El-Sayed MA. Chemistry and properties of nanocrystals of different shapes. Chem Rev. 2005;105(4): $1025-1102$.

2. Chen S, Carroll DL. Silver nanoplates: size control in two dimensions and formation mechanisms. $J$ Phys Chem B. 2004;108(18):5500-5506.

3. Hoelderich WF. Environmentally benign manufacturing of fine and intermediate chemicals. Catal Today. 2000;62(1):115-130.

4. Hu J, Odom TW, Lieber CM. Chemistry and physics in one dimension: synthesis and properties of nanowires and nanotubes. Acc Chem Res. 1999;32(5):435-445.

5. Petica A, Gavriliu S, Lungu M, Buruntea N, Panzaru C. Colloidal silver solutions with antimicrobial properties. Mater Sci Eng B. 2008;152(1-3):22-27.

6. El-Sayed MA. Some interesting properties of metals confined in time and nanometer space of different shapes. Acc Chem Res. 2001;34(4):257-264.

7. Zhu Y, Shi J, Shen W, et al. Stimuli-responsive controlled drug release from a hollow mesoporous silica sphere/polyelectrolyte multilayer core-shell structure. Angew Chem Int Ed. 2005;44(32): 5083-5087.

8. Wei W, Ma GH, Hu G, et al. Preparation of hierarchical hollow $\mathrm{CaCO}_{3}$ particles and the application as anticancer drug carrier. JAm Chem Soc. 2008;130(47):15808-15810.

9. Korobko AV, Jesse W, van der Maarel JR. Encapsulation of DNA by cationic diblock copolymer vesicles. Langmuir. 2005;21(1): $34-42$.

10. Chen J, Wiley B, McLellan J, Xiong Y, Li ZY, Xia Y. Optical properties of Pd-Ag and Pt-Ag nanoboxes synthesized via galvanic replacement reactions. Nano Lett. 2005;5(10):2058-2062.

11. Chen CW, Serizawa T, Akashi M. Preparation of platinum colloids on polystyrene nanospheres and their catalytic properties in hydrogenation. Chem Mater. 1999;11(5):1381-1389.

12. Jenekhe SA, Chen XL. Self-assembly of ordered microporous materials from rod-coil block copolymers. Science. 1999;283(5400): 372-375.

13. Zhang S. Fabrication of novel biomaterials through molecular selfassembly. Nat Biotechnol. 2003;21(10):1171-1178.

14. Zhu LP, Liao GH, Yang Y, Xiao HM, Wang JF, Fu SY. Self-assembled 3D flower-like hierarchical beta- $\mathrm{Ni}(\mathrm{OH})(2)$ hollow architectures and their in situ thermal conversion to NiO. Nanoscale Res Lett. 2009;4(6): $550-557$.

15. Sun Y, Mayers B, Herricks T, Xia Y. Polyol synthesis of uniform silver nanowires: a plausible growth mechanism and the supporting evidence. Nano Lett. 2003;3(7):955-960.

16. Sun Y,Yin Y, Mayers BT, Herricks T, Xia Y. Uniform silver nanowires synthesis by reducing $\mathrm{AgNO}_{3}$ with ethylene glycol in the presence of seeds and poly(vinyl pyrrolidone). Chem Mater. 2002;14(11):4736-4745.

17. Murphy CJ, Jana NR. Controlling the aspect ratio of inorganic nanorods and nanowires. Adv Mater. 2002;14(1):80-82.

18. Wiley B, Sun Y, Xia Y. Synthesis of silver nanostructures with controlled shapes and properties. Acc Chem Res. 2007;40(10):1067-1076.

19. Ni C, Hassan PA, Kaler EW. Structural characteristics and growth of pentagonal silver nanorods prepared by a surfactant method. Langmuir. 2005;21(8):3334-3337.

20. Liong M, Lu J, Kovochich M, et al. Multifunctional inorganic nanoparticles for imaging, targeting, and drug delivery. ACS Nano. 2008;2(5): 889-896.

21. Lou XW, Archer LA, Yang Z. Hollow micro-/nanostructures: synthesis and applications. Adv Mater. 2008;20(21):3987-4019.

22. Horcajada P, Rámila A, Pérez-Pariente J, Vallet-Regí M. Influence of pore size of MCM-41 matrices on drug delivery rate. Microporous Mesoporous Mater. 2004;68(1-3):105-109. 
23. Limnell T, Riikonen J, Salonen J, et al. Surface chemistry and pore size affect carrier properties of mesoporous silicon microparticles. Int J Pharm. 2007;343(1-2):141-147.

24. Pal S, Tak YK, Song JM. Does the antibacterial activity of silver nanoparticles depend on the shape of the nanoparticle? A study of the gram-negative bacterium Escherichia coli. Appl Environ Microbiol. 2007;73(6):1712-1720.
25. Zhou W, Ma Y, Yang H, Ding Y, Luo X. A label-free biosensor based on silver nanoparticles array for clinical detection of serum p53 in head and neck squamous cell carcinoma. Int J Nanomedicine. 2011;6: 381-386.

26. Shanmukh S, Jones L, Driskell J, Zhao Y, Dluhy R, Tripp RA. Rapid and sensitive detection of respiratory virus molecular signatures using a silver nanorod array SERS substrate. Nano Lett. 2006;6(11):2630-2636.

\section{Publish your work in this journal}

The International Journal of Nanomedicine is an international, peerreviewed journal focusing on the application of nanotechnology in diagnostics, therapeutics, and drug delivery systems throughout the biomedical field. This journal is indexed on PubMed Central, MedLine, CAS, SciSearch $\AA$, Current Contents ${ }^{\circledR} /$ Clinical Medicine,
Journal Citation Reports/Science Edition, EMBase, Scopus and the Elsevier Bibliographic databases. The manuscript management system is completely online and includes a very quick and fair peer-review system, which is all easy to use. Visit http://www.dovepress.com/ testimonials.php to read real quotes from published authors. 